\title{
Cell biological and molecular characteristics of pseudorabies virus infections in cell cultures and in pigs with emphasis on the respiratory tract
}

\author{
Hans NAUWYNCK* ${ }^{*}$ Sarah GloriEUX, Herman FAVOREEL, \\ Maurice PENSAERT
}

Laboratory of Virology, Faculty of Veterinary Medicine, Ghent University, Salisburylaan 133, 9820 Merelbeke, Belgium

(Received 13 June 2006; accepted 23 November 2006)

\begin{abstract}
In the present review, several cell biological and molecular aspects of virus-cell and virus-host (pig) interactions are reviewed for pseudorabies (Aujeszky's disease) virus. Concerning the virus-cell interactions, the complex cascade of events in the virus replication cycle is given together with the different mechanisms of cell-to-cell spread. The pathogenesis of pseudorabies virus infections in pigs is concentrated on the sequence of events in the respiratory tract. Finally, a short overview is given on the control of the disease and eradication of the virus by the combination of marker vaccines and discriminating ELISA.
\end{abstract}

pseudorabies virus / virus replication / cell-associated spread / pathogenesis / control

\section{Table of contents}

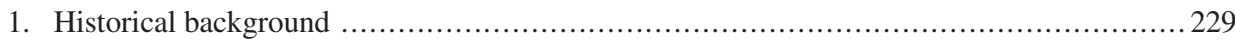

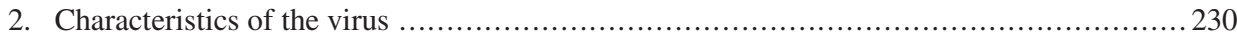

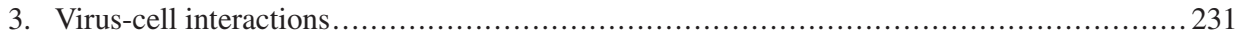

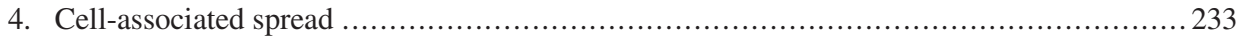

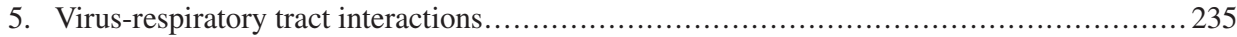

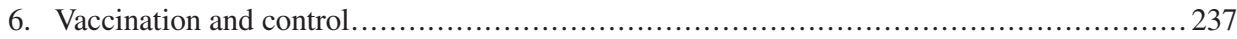

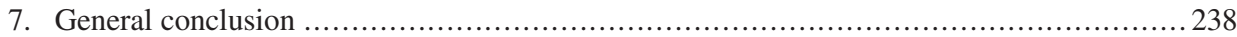

\section{HISTORICAL BACKGROUND}

Aujeszky's disease or pseudorabies is a disease with a long history. In the nineteenth century, the disease was linked with central nervous disorders in cattle, dogs and cats, characterized by itching, rubbing,

* Corresponding author: hans.nauwynck@ugent.be exhaustion and paralysis. At that time, pigs did not come into the picture. In the USA, the oldest descriptions of a disease that closely resembles Aujeszky's disease was called "mad-itch" in cattle and was referred to in the agricultural magazines "Cultivator" (1839) and "New England Farmer" (1844) [17]. Similar reports were made later in Europe. In 1889, Strebel [64] 


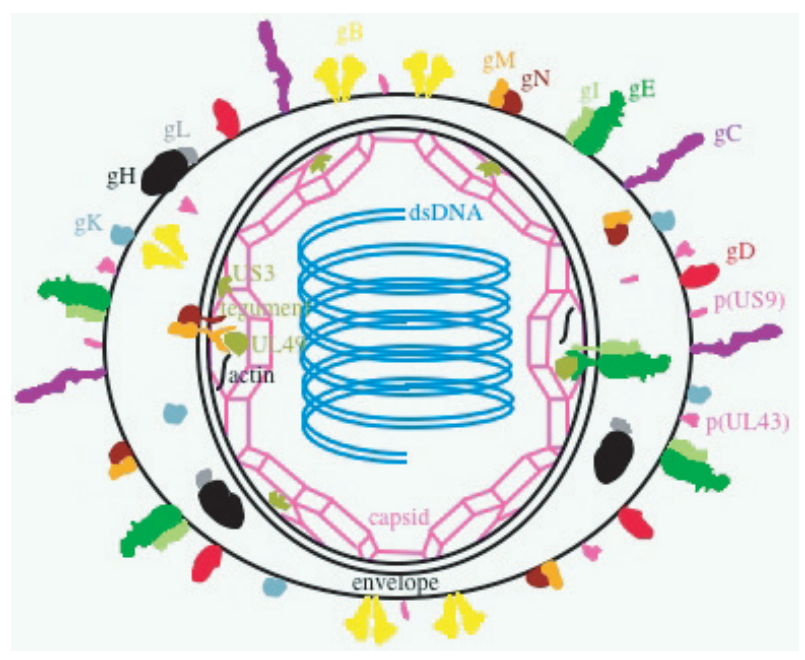

Figure 1. Structure of a pseudorabies virion. published his findings on four cows with itching in Switzerland ("Juckkrankheit") and mentioned that he had seen five similar cases in the past in his region. The Hungarian veterinary surgeon Aladar Aujeszky was the first to demonstrate the infectious origin of the disease and to forward the idea that the disease was distinct from rabies [2]. He could induce nervous symptoms and death in rabbits within a period of $48 \mathrm{~h}$ with tissue suspensions from an ox with the following clinical picture: excitation and nasal pruritus, followed by convulsions and death within half a day. He was successful in repeating his experiment with brain material from a cat and a dog which died quickly after showing similar symptoms. Aujeszky was convinced that he dealt with a virus that was different from rabies virus based on some specific observations, such as short time of incubation, quick course of disease and infectivity of blood. Afterwards, Schmiedhofer (1910) [58], Shope (1931 and 1934) [60,61] and Elford and Galloway (1936) [10] brought the necessary proofs to demonstrate that a virus with a size between $100-150 \mathrm{~nm}$ was the cause of the disease based on ultrafiltration experiments. Reagan et al. were the first to visualize the virus (1952) [54].
Based on immunological studies, virus morphology, intranuclear inclusions and ether sensitivity, Sabin (1934) [55] and Kaplan and Vatter (1959) [21] classified Aujeszky's disease virus (ADV)/pseudorabies virus (PrV) in the herpesvirus group. PrV was linked with sporadic problems in pigs world-wide and pigs were identified as a reservoir between 1920 and 1940 [30]. During the intensification of pig breeding in the nineteen-fifties, nineteen-sixties and nineteen-seventies, increasing incidences of severe clinical outbreaks were reported in swine. Several pig specialists are convinced that an increase in virulence occurred during this period, however a cell biological and molecular explanation is lacking.

\section{CHARACTERISTICS OF THE VIRUS}

PrV belongs to the family of the Herpesviridae, subfamily Alphaherpesvirinae, genus Varicellovirus. The general structure of a pseudorabies virion is given in Figure 1. The virion consists of a double stranded DNA genome of approximately 
$150 \mathrm{kbp}$, surrounded by a capsid, tegument and envelope.

The genome of PrV belongs to the class $\mathrm{D}$ genomes of the herpesviruses. It consists of two unique regions, a long one (unique long, $\mathrm{U}_{\mathrm{L}}$ ) and a short one (unique short, $U_{S}$ ) flanked by two repeat sequences, an internal one (IRS) and a terminal one (TRS) [4]. The whole genome has been sequenced and published by Klupp et al. [28].

The different genes within the genome of the alphaherpesviruses are designated by a two letter code UL or US depending on its position in the unique long $\left(\mathrm{U}_{\mathrm{L}}\right)$ or unique short $\left(\mathrm{U}_{\mathrm{S}}\right)$, followed by a number. The number gives the place of the gene within each specific region.

The capsid of alphaherpesviruses encloses and protects the large genome. It consists of 162 capsomers, 150 hexons (one hexon consists of 6 molecules VP5 (protein expressed by UL19 (pUL19)) and 6 molecules VP26 (p(UL35)) and 12 pentons (11 pentons consist of 5 molecules of VP5 ( $\mathrm{p}(\mathrm{UL} 19))$; 1 penton consists of 12 molecules of $\mathrm{p}$ (UL6) and forms the cylindric entry pore for newly produced dsDNA), both linked by triplexes (one molecule of VP19C ( $\mathrm{p}$ (UL38)) and two molecules of VP23 (p(UL18))), all nicely arranged in an icosahedral lattice [44]. The space between the capsid and the envelope is filled with tegument proteins, which comprise besides viral proteins cellular actin. Tegument proteins are important during entry, priming the cell for virus replication, primary envelopment at the inner nuclear membrane and secondary envelopment at trans-Golgi vesicles [38]. The envelope is a bilayered phospholipid membrane which is pinched off from the cell membrane during assembly at transGolgi vesicles. It contains 10 glycoproteins $(\mathrm{gB}, \mathrm{gC}, \mathrm{gD}, \mathrm{gE}, \mathrm{gH}, \mathrm{gI}, \mathrm{gK}, \mathrm{gL}$, $\mathrm{gM}, \mathrm{gN}$ ) with $\mathrm{gB}$ forming homodimers, $\mathrm{gE} / \mathrm{gI}, \mathrm{gH} / \mathrm{gL}$ and $\mathrm{gM} / \mathrm{gN}$ forming heterooligomers [36] and at least 2 nonglyco- sylated proteins (p(UL43), p(US9)) [7,29]. The envelope proteins play important roles in binding, internalization, envelopment, egress, cell-associated spread, induction of protective immunity and immune evasion. Different domains in both the extra- and intra-envelope regions are important for these functions.

\section{VIRUS-CELL INTERACTIONS}

An overview of the PrV replication is given in Figure 2. PrV has developed an ingenious complex system to enter a host cell. It consists of a cascade of interactions between viral and cellular components. The attachment is initiated by an unstable binding mediated by the viral envelope glycoprotein $\mathrm{gC}$ and cellular heparan sulfate proteoglycans exposed at the plasma membrane [35]. Next, PrV is firmly bound to the cell by glycoprotein $\mathrm{gD}$ which is interacting with at least one of three cellular receptors: nectin 1 , nectin 2 and CD55 [37, 63]. The presence of different receptors for $\mathrm{gD}$ may explain the extreme pantropic character of PrV and the possibility to infect non-porcine mammals. Binding is followed by fusion coordinated by $\mathrm{gB}, \mathrm{gD}$ and $\mathrm{gH} / \mathrm{gL}$ which all probably find their own not yet identified cellular counterparts $[26,53]$. Next, capsids of alphaherpesviruses are transported to the nucleus via microtubules [62].

Upon arrival in the nucleus, the PrV genome is transcribed in a cascade-like fashion [4]. First, immediate-early (IE) genes are transcribed during the first $2 \mathrm{~h}$ after nucleus entry. For this transcription the host nuclear machinery is used. IE180 is the only PrV IE protein. It is activating not only promoters of PrV genes (US4(gG), UL12(deoxyribonuclease), UL22(gH), UL23(thymidine kinase) and UL41(viral host shut off)) but also promoters of cellular genes and genes of other viruses (cross-activation) $[8,46,65,73,74]$. 


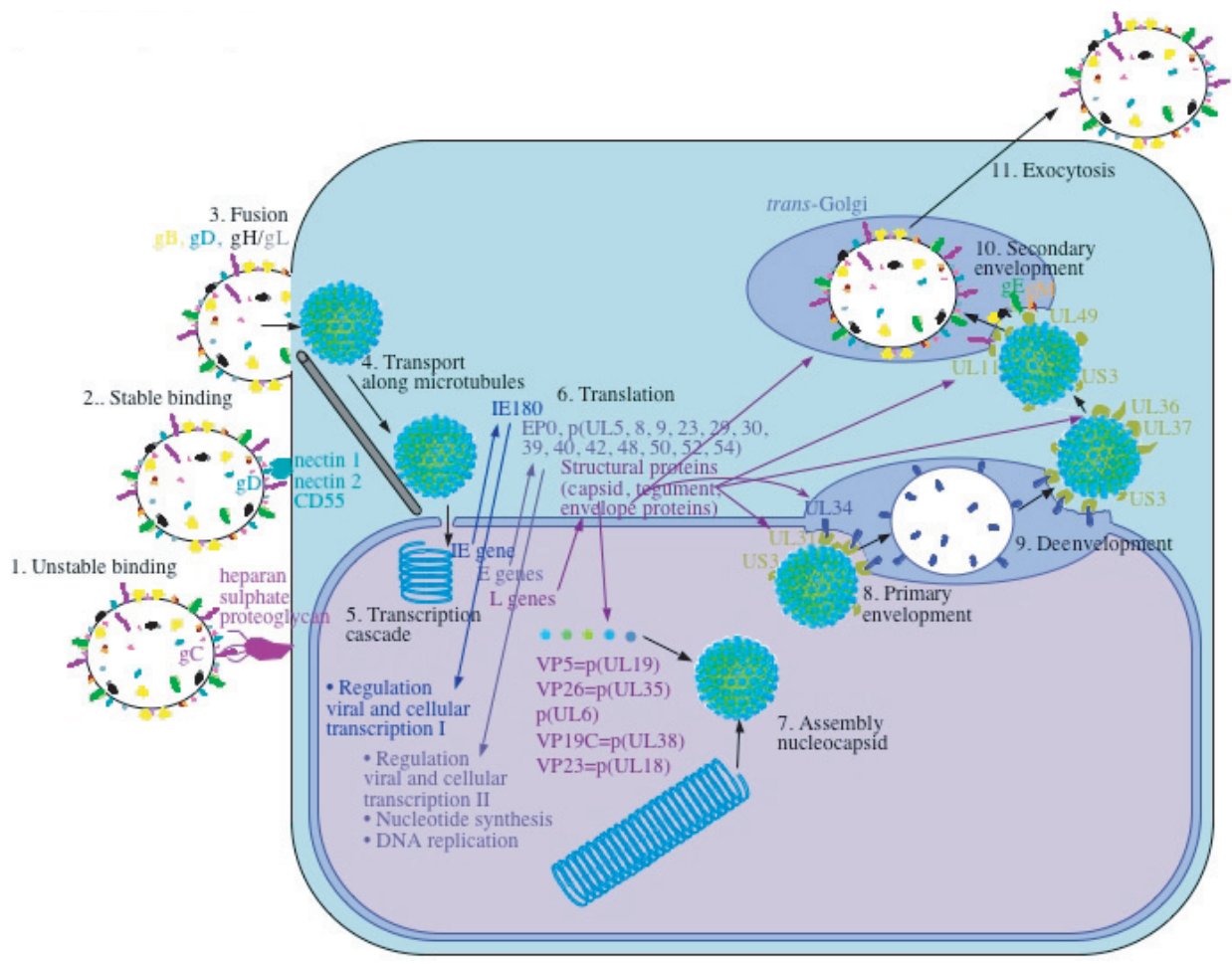

Figure 2. PrV replication cycle.

Early (E) genes are the next group of genes that are active. Like IE180, several of them (EP0, UL54 and UL48) are regulating the expression of genes of PRV and the cell [13, 45, 59]. Other E genes are producing proteins which are important for nucleotide synthesis (UL23, UL39/UL40, UL50) and DNA replication (UL5, UL8, UL9, UL29, UL30, UL42, UL52). The UL23-encoded thymidine kinase is phosphorylating deoxythymidine into deoxythymidine-triphosphate, one of the four building stones of DNA. This non-essential enzyme in cell cultures is important for the replication of $\mathrm{PrV}$ in differentiated cells such as neurons in vivo [25]. UL39 and UL40 products are forming a viral ribonucleotide reductase, which reduces ribonucleotides into deoxyribonucleotides [22]. The absence of this enzyme strongly attenuates the virus for replication in pigs [9]. The UL50 encodes a dUTPase which is cleaving dUTP into dUMP and pyrophosphate. dUMP may be enzymatically changed into dTMP and subsequently into dTTP. Deletion of UL50 results in a reduced virus replication in pigs [20]. In analogy with herpes simplex virus, the proteins encoded by UL5, UL8 and UL52 are predicted to form a heterotrimeric primase-helicase complex, which together with $\mathrm{p}$ (UL9), is believed to recognize the site of initiation of DNA synthesis and unwinds the supercoiled DNA [33]. Products of UL30 and UL42 form the DNA-dependent DNA polymerase which uses the rolling-circle mechanism to produce a long head-to-tail concatemeric DNA strand [5]. The precise mechanism is still not completely 
understood, and still controversially discussed. Finally late (L) genes become expressed. They mainly encode structural proteins, such as capsid and tegument proteins and envelope (glyco)proteins. All capsid proteins enter the nucleus for the formation of the capsids. Scaffolding proteins encoded by UL26 and UL26.5 aid in the construction of the capsids. The concatemeric DNA is cleaved into monomeric forms and simultaneously pulled into newly formed capsids through the cylindric entry pore encoded by UL6 (special penton of the capsid).

The nucleocapsid is then ready for the primary envelopment at the inner nuclear membrane and subsequent deenvelopment at the outer nuclear membrane. At least three viral proteins encoded by US3, UL34 and UL31 have been put forward to be crucial players in this process [38]. The following steps are proposed: $\mathrm{p}(\mathrm{UL} 31)$ is a tegument protein which takes care of the first positioning of the nucleocapsids at the inner membrane where $p$ (UL34), a transmembrane protein, is anchored. By budding, primary enveloped particles are entering the lumen and by fusion the nucleocapsids are released in the cytoplasm [14]. Next, the nucleocapsids are transported to the trans-Golgi vesicles, the site for the secondary envelopment process. The cytoskeletal structures and motor proteins necessary for the transport to this site are not characterized yet. It is very well possible that tegument proteins encoded by US3, UL36 and UL37 which are found on the outside of cytoplasmic nucleocapsids, are involved in this migration with $\mathrm{p}(\mathrm{UL} 36)$ physically interacting with p(UL37) [16,27]. The envelope glycoproteins are anchored in the membranes of TGN vesicles, presenting their cytoplasmic tails in the cytosol. On these tails, tegument proteins are assembled. P(UL11) and $\mathrm{p}$ (UL49) have already been localized at this site. The latter tegument protein in- teracts with the tails of $\mathrm{gE}$ and $\mathrm{gM}$ [15]. Finally, the virus is released by exocytosis.

\section{CELL-ASSOCIATED SPREAD}

Herpesviruses have developed a strong cell-associated way of spreading which may allow them to escape from extracellular detrimental molecules, such as antibodies, complement and enzymes and the elimination by phagocytes. This way of spreading is clearly visible both in vitro and in vivo by the presence of plaques/foci of infected cells. Several mechanisms of the cell-associated spread have been described. They are summarized in Figure 3. A first one is fusion of cells in contact with direct spread of PrV from an infected cell to a noninfected neighboring cell. Viral glycoproteins that are expressed in the plasma membrane of the infected cell and their respective receptors on the plasma membrane of the uninfected cell mediate this process. For PrV, the envelope glycoproteins $\mathrm{gB}, \mathrm{gH} / \mathrm{gL}$ and $\mathrm{gK}$ are essential while $\mathrm{gE} / \mathrm{gI}$ and $\mathrm{gM}$ are not essential, but modulating [36]. Three other mechanisms of cell-associated spread of $\mathrm{PrV}$ have been described between distant cells.

(i) PrV may spread in a cell-associated way between distant cells after viral induced formation of protrusions [12]. For this process, complex interactions between cellular and viral components are involved of which only a few pieces of the puzzle have been found. In vitro, PrV infection of a cell has been shown to cause a complete re-organization of the actin architecture $[12,69]$. Stress fibers break down and new cellular protrusions are formed which make contact with neighboring cells. The viral serine/threonine protein kinase US3 plays a crucial role in this remodeling process. Newly formed virus particles are transported to the end of the protrusions, where the virus may enter the neighboring cell. Whether a fusion process occurs 
A. Between cells in contact by fusion process with the formation of a syncytium (dark green: essential; light green: modulating)
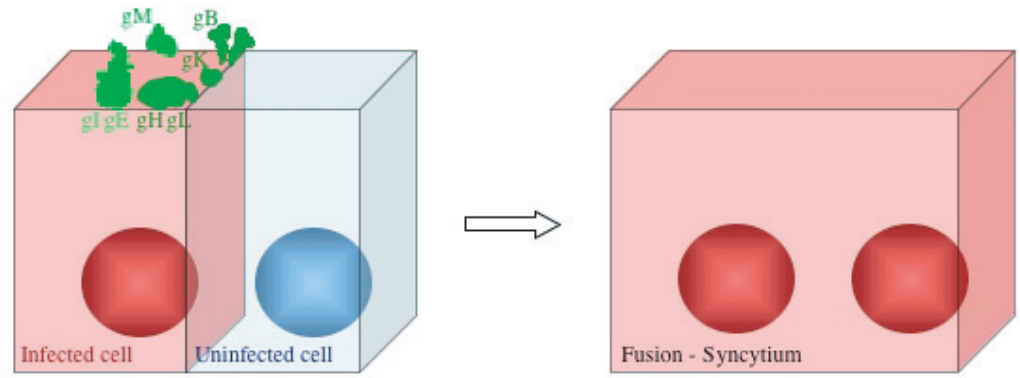

B. Between distant cells by the formation of a protrusion (intercellular bridge)
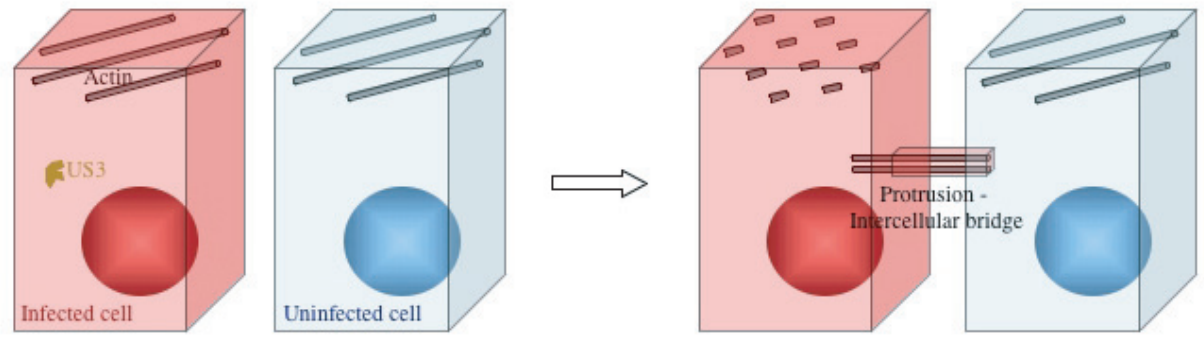

C. Between distant cells upon virus-mediated binding and fusion
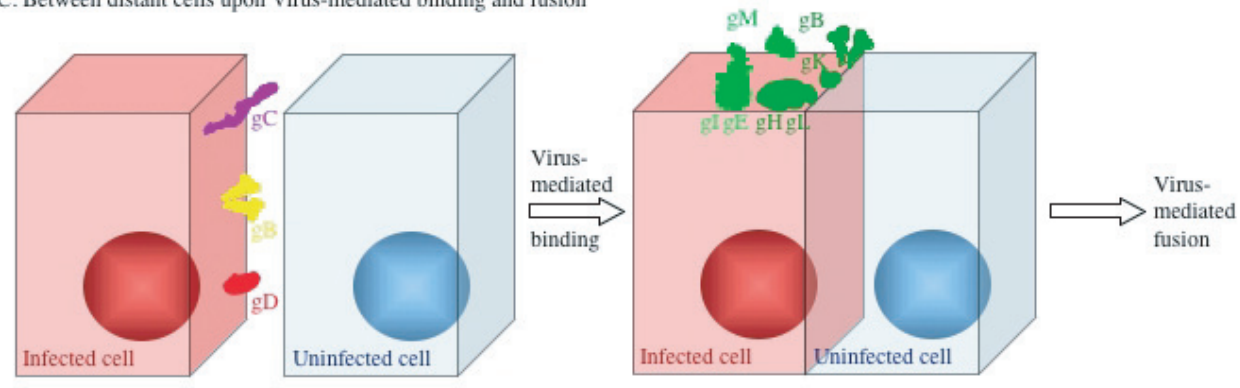

D. Between distant cells upon cell-mediated binding and virus-mediated fusion
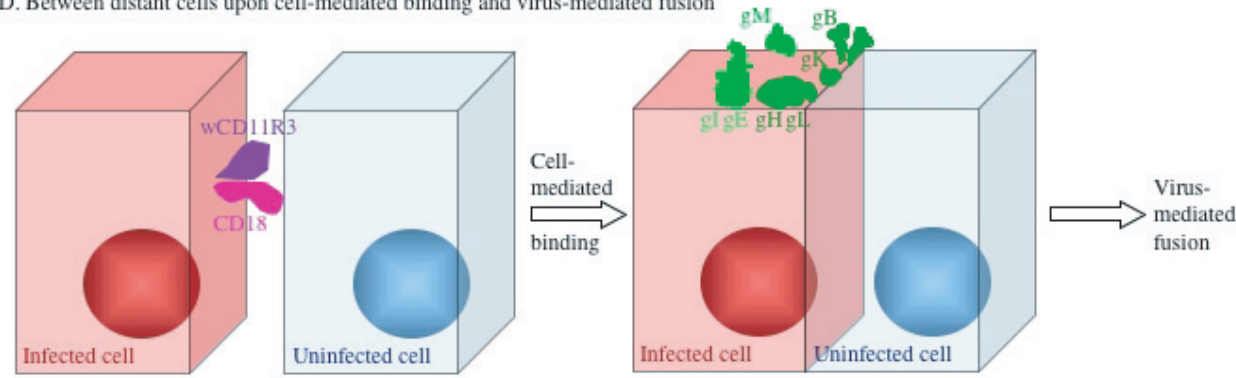

Figure 3. Different mechanisms of cell-associated spread of PrV. 
between the end of the protrusion and the plasma membrane of the neighboring cell is not known.

(ii) Also in vitro it has been demonstrated that PrV infected cells in suspension express viral envelope glycoproteins on their surface and via these proteins attach to and fuse with non-infected neighboring cells [18]. The mechanism of this process closely resembles the virus-cell attachment and fusion.

(iii) PrV cell-associated spread between distant cells may also occur after attachment that is mediated by cellular adhesion molecules. Such attachment has already been described between PrVinfected monocytes and endothelial cells [67]. PrV-infected monocytes that have been exposed to virus-specific antibodies internalize their viral glycoproteins together with their MHCI molecules, leaving cells that are masked from efficient recognition and elimination by different components of the immune system $[11,68]$. These immune-masked monocytes have been shown to adhere specifically to endothelial cells by the cellular adhesion molecules wCD11R3 and CD18. This cellmediated attachment is followed by a viralmediated fusion process, leading to the spread of PrV to the endothelial cell [67].

\section{VIRUS-RESPIRATORY TRACT INTERACTIONS}

The general pathogenesis picture of PrV infections in pigs can be summarized as follows. The virus primarily replicates in the respiratory tract, especially the upper respiratory tract, spreads along cranial nerves to the brains and via lymph and blood to internal organs, with the reproductive organs being important targets. Replication in the respiratory tract, central nervous system and reproductive organs is responsible for pathological changes caus- ing respiratory, nervous and reproductive disorders.

Clear changes in virus-host interactions have been reported over time which point to differences in virulence of the virus. The original reports of Aujeskzy's disease were only describing nervous disorders, mainly in cattle and dogs and rarely in pigs. The involvement of the respiratory tract in the pathogenesis was not at all clear at that moment. Shope (1934) [69] was the first one to demonstrate that PrV was present in nasal secretions of pigs for several days after intranasal infection and Mc Ferran and Dow (1964) [34] showed that PrV was shed from 1 to 9 days after inoculation in the nasal secretions and up to 17 days intermittently. Researchers of the Veterinary Research Laboratories (Stormont, Belfast, Northern Ireland) discovered clear pathogenetic changes between strains which were isolated in their region over time. The Northern Ireland PrV strain 1 (NIA-1) originally isolated in the nineteen-sixties was found to replicate in the nasal and pharyngeal mucosa starting from $24 \mathrm{~h}$ post inoculation. During the replication of at least one week, no respiratory disease and gross pathological lesions were found in the respiratory tract. After $48 \mathrm{~h}$, virus was detected in the central nervous system where it was spreading over time. The dissemination via lymph and blood and replication in internal organs was very restricted. The pathogenesis of infections with NIA-2, which was isolated one decade later, behaved somewhat similar. The more pronounced respiratory lesions (rhinitis and pneumonia) were attributed to the way of inoculation [3]. The virus was administered via aerosol, which allows the virus to reach deeper parts of the respiratory tract than when the virus is instilled intranasally. NIA-3 was isolated in the early nineteen-seventies during a severe outbreak, with $100 \%$ mortality in piglets during their first weeks of age. Several sows aborted. The extremely high 
mortality in piglets and abortions were new findings at that time. This strain was highly virulent for the respiratory tract. As soon as $30 \mathrm{~h}$ after intranasal inoculation, pyrexia was measured and $48 \mathrm{~h}$ post inoculation, severe depression, tremors of the extremities and sneezing with a mucopurulent nasal discharge were noticed [51]. Pathologically, the nasal and pharyngeal mucosae were hyperemic at $24 \mathrm{~h}$ post inoculation and necrotic starting from $48 \mathrm{~h}$ post inoculation. This extremely aggressive form of Aujeszky's disease was not reported before. Virologically, the virus had spread within $24 \mathrm{~h}$ through the basement membrane and was already replicating in several fibrocytes in the lamina propria. At $48 \mathrm{~h}$ post inoculation, the epithelial cells were sloughed away and large parts of the underlying connective tissue were necrotic.

In the nineteen-sixties-seventies, an increase in the invasive character of PrV at the level of the respiratory tract allowing the virus to find access to more nerves and to increase the viremia and to replicate to high levels in internal organs, including reproductive organs, was also reported in other countries. In Belgium, a virulence switch has been recognized in the beginning of the nineteen-seventies [47]. A strain isolated in 1971 (NS374) from a few piglets with central nervous disorders but without a high mortality, respiratory problems and reproductive problems on the farm of origin, was inoculated in piglets of 7 weeks of age. A restricted replication was found in the respiratory tract. A viremia was not detected and in the central nervous system the virus could only be demonstrated in the brainstem. Besides fever, other clinical signs were not observed. In contrast, the 75V19 strain, which was isolated during a severe PrV outbreak with respiratory, nervous and reproductive problems in 1975, was replicating to higher titers in the respiratory tract compared to the NS374, gave a clear viremia and was replicating in different regions of the central nervous system. Similar observations of increased virulence were done in other West European countries $[1,50,66]$. The basis for the increased virulence is not known. Interesting are the observations made by Bitsch (1980) [6] in Denmark. A link was made between the characteristics in vitro and the behavior in the field. The more invasive strains demonstrated a better cell-associated spread (larger syncytia). A similar finding was done with Belgian strains [42]. Over time, the cell-associated spread of PrV isolates seems to have improved. In one way or another there seems to be an advantage in evolution for PrV to spread in a cell-associated way.

The replication kinetics and characteristics of $\mathrm{PrV}$ in the respiratory tract are influenced by different factors, such as virus strain as illustrated above, inoculation route, virus titer in the inoculum, animal age and genetics and immune status. In naïve pigs, PrV replicates first in the respiratory tract, mainly in the upper part, consisting of the nasal cavity, tonsils and the oropharynx upon intranasal/peroral inoculation. It infects primarily the epithelial cells and within $24 \mathrm{~h}$ it crosses the basement membrane in order to infect all cell types in the underlying tissues in a plaquewise fashion (fibrocytes, endothelial cells, mononuclear cells) [31, 32, 39, 56, 57, 72]. How the virus penetrates easily through the mucus layer barrier on top of the epithelial cells and crosses the basement membrane barrier is not known and deserves more indepth studies. Replication in lower parts of the respiratory tract is restricted, except when virus is directly deposited in these locations, such as by intratracheal or aerosol inoculation $[3,39]$. In the lungs, the virus replicates in all epithelial cell types and spreads plaque-wise without restrictions [39]. Lung macrophages have also been identified as target cells [19]. Between 2 and 5 days post inoculation, virus spreads in a cell-associated way over the 
whole mucosa and deep into the submucosa. Virus replication induces an enormous influx of phagocytes which as a first line defense start to attack the infected regions. The resulting massive destruction causes respiratory signs, such as sneezing, coughing, nasal discharge and dyspnea. During this invasion period, virus becomes transported over neurons, in blood and lymphatics and reaches important target organs such as the brain, lymphoid organs and pregnant uterus. Interferon-alpha is present starting from 2 till 7 days post inoculation and the concentration is inversely proportional to the intranasal virus replication [43]. The latter shows the importance of interferon-alpha in the control of virus replication in the nose and pharynx. Using nasal mucosal explants, Pol et al. [52] demonstrated that interferon-alpha is diminishing the spread of PrV in the connective tissue but not in the epithelial cells. The reason why epithelial cells are not protected is not understood and should be further analyzed. With the appearance of a general and local humoral and cellular immunity starting from 6-7 days post inoculation, virus becomes neutralized and inactivated and infected cells are lysed and cleared by phagocytes [24]. With the onset of the specific immunity, the recovery phase starts. Despite the presence of these different arms of the immune system, virus is completely eliminated only after 13 days post inoculation in the nasal cavity and 18 days post inoculation from the tonsils $[48,70]$. The ability to replicate at a low level in the presence of a specific immunity is indicative for the fact that $\mathrm{PrV}$ is able to overcome some antiviral actions of the immunity. This also forms the basis for replication of $\mathrm{PrV}$ in the respiratory tract of immune animals after previous infection or vaccination or after uptake of colostrum with anti-PrV antibodies. A reduced number of small foci of virus replication are still present in the respiratory tract, virus may still reach the trigeminal ganglion and virus may still be spread via infected monocytes in the blood. During the latter cell-associated viremia virus may still cross the placenta and infect fetuses [41]. The stronger the immune response and the more components of the immunity are activated, the better the protection.

By using mutants, it is possible to study the role of certain non-essential viral envelope glycoproteins and viral enzymes in the replication and invasion capacities. PrV $\mathrm{gC}$ and gI negative mutants behaved like the wild type virus with respect to the number and size of the foci of infected cells in the mucosa/submucosa. In contrast, the absence of $\mathrm{gE}$ and $\mathrm{gD}$ resulted in a reduced number of infected cells and gave foci with smaller dimensions [31, 32, 40]. Concerning the enzymes, it was demonstrated that the absence of viral ribonucleotide reductase, dUTPase and US3-encoded protein kinase was reducing virus excretion in pigs, indicating that the replication was clearly affected $[9,20,23]$. At what level these proteins are involved in the invasion of PrV through the different layers of the respiratory mucosa and submucosa is not known and merits further examination.

\section{VACCINATION AND CONTROL}

In order to guarantee a free trade of pigs in Europe, efforts have been made to eradicate PrV [49]. In the past, PrV hindered free trade between countries such as Great Britain and several Scandinavian countries which were already free for decades by mainly a stamping out policy and countries which were not free and wanted to export pigs to PrV free countries. Therefore, several exporting countries started programs to reach a PrV free status. For reaching this high sanitary status, huge efforts were necessary, especially in densely populated pig regions where the seroprevalence was high. In most of these regions a combination of vaccination during several years, 
which reduced virus circulation and seroprevalence, and culling at a moment of low seroprevalence was used, generally with success. This whole strategy was only possible with marker vaccines and a discriminating ELISA which is able to identify infected animals in a group of vaccinated animals [71]. For PrV, the choice fell on a $\mathrm{gE}$ deletion vaccine, based on several molecular features. Deleting gE is attenuating PrV by reducing the cell-associated transmission and neurological spread but does not hinder mass production in cell cultures and does not show a reduced induction of a protective immunity. Because latent virus may be reactivated and cause a new explosion of transmissions, it was generally feared that eradication programs would have met a lot of problems to be successful. This fear seemed to be unfounded in the field.

At present, the following countries are officially PrV free: Finland, Norway, Sweden, Denmark, Great Britain, Luxembourg, Switzerland, Austria and Germany. The Netherlands, Belgium and France are gEnegative and are making plans to stop vaccination. It can be predicted that these countries will get the "officially PrV free status" by the end of 2007. Since PrV is still present in wild boars and feral swine in most of these countries, authorities should follow up the situation within this population and estimate the risk from this reservoir in the wild.

\section{GENERAL CONCLUSION}

PrV has gathered during evolution a lot of tools to infect a broad range of cells and to spread in between cells in a cellassociated way. These characteristics allow PrV to invade quickly through the different layers of the mucosa and submucosa at the site of entry, the upper respiratory tract and to subsequently reach neurons and blood vessels, via which internal organs can be reached. Despite these features in favor of the virus, it is possible to eradicate PrV by an intensive vaccination with gE-negative vaccines followed by culling of the $\mathrm{gE}$ positive animals.

\section{REFERENCES}

[1] Akkermans J.P., Aujeszky's disease in the Netherlands, Pig Vet. Soc. Proc. (1980) 5:59-67.

[2] Aujeszky A., Ueber eine neue Infektionskrankheit bei Haustieren, Zbl. Bakteriol. Infektionskrankh. Parasitenkde. 1. Abt. Orig. (1902) 32:353-357.

[3] Baskerville A., The histopathology of pneumonia produced by aerosol infection of pigs with a strain of Aujeszky's disease virus, Res. Vet. Sci. (1971) 12:590-592.

[4] Ben-Porat T., Kaplan A.S., Molecular biology of pseudorabies virus, in: Roizman B. (Ed.), The Herpesviruses, Plenum press, 1985, Vol. 3, pp. 105-173.

[5] Berthomme H., Monahan S.J., Parris D.S., Jacquemont B., Epstein A.L., Cloning, sequencing and functional characterization of the two subunits of the pseudorabies virus DNA polymerase holoenzyme: evidence for specificity of interaction, J. Virol. (1995) 69:2811-2818.

[6] Bitsch V., Correlation between the pathogenicity of field strains of Aujeszky's disease virus and their ability to cause cell fusion - syncytia formation - in cell cultures, Acta Vet. Scand. (1980) 21:708-710.

[7] Brideau A.D., Banfield B.W., Enquist L.W., The Us9 gene product of pseudorabies virus, an alphaherpesvirus, is a phosphorylated tailanchored type II membrane protein, J. Virol. (1998) 72:4560-4570.

[8] Chang Y.Y., Lin H.W., Wong M.L., Chang T.J., Regulation of the vhs gene promoter of pseudorabies virus by IE180 and EP0, and the requirement of a $\mathrm{Sp} 1$ site for the promoter function, Virus Genes (2004) 28:247258.

[9] De Wind N., Berns J., Gielkens A.L., Kimman T.G., Ribonucleotide reductasedeficient mutants of pseudorabies virus are avirulent for pigs and induce partial protective immunity, J. Gen. Virol. (1993) 74:351359. 
[10] Elford W.J., Galloway I.A., The size of the virus of Aujeszky's disease ("pseudorabies", "infectious bulbar paralysis", "mad itch") by ultrafiltration analysis, J. Hyg. (Cambr.) (1936) 36:536-539.

[11] Favoreel H.W., Nauwynck H.J., Halewyck H.M., Van Oostveldt P., Mettenleiter T.C., Pensaert M.B., Antibody-induced endocytosis of viral glycoproteins and major histocompatibility complex class I on pseudorabies virus-infected monocytes, J. Gen. Virol. (1999) 80:1283-1291.

[12] Favoreel H.W., Van Minnebruggen G., Adriaensen D., Nauwynck H.J., Cytoskeletal rearrangements and cell extensions induced by the US3 kinase of an alphaherpesvirus are associated with enhanced spread, Proc. Natl. Acad. Sci. USA (2005) 102:8990-8995.

[13] Fuchs W., Granzow B.G., Klupp B.G., Kopp M., Mettenleiter T.C., The UL48 tegument protein of pseudorabies virus is critical for intracytoplasmic assembly of infectious virus, J. Virol. (2002) 76:6729-6742.

[14] Fuchs W., Klupp B.G., Granzow H., Osterrieder N., Mettenleiter T.C., The interacting UL31 and UL34 gene products of pseudorabies virus are involved in egress from the host-cell nucleus and represent components of primary enveloped but not of mature virions, J. Virol. (2002) 76:364-378.

[15] Fuchs W., Klupp B.G., Granzow H., Hengartner C., Brack A., Mundt A., Mettenleiter T.C., Physical interaction between envelope glycoproteins $\mathrm{E}$ and $\mathrm{M}$ of pseudorabies virus and the major tegument protein UL49, J. Virol. (2002) 76:8208-8217.

[16] Fuchs W., Klupp B.G., Granzow H., Mettenleiter T.C., Essential function of the pseudorabies virus UL36 gene product is independent of its interaction with the UL37 protein, J. Virol. (2004) 78:11879-11889.

[17] Hanson R.P., The history of pseudorabies in the United States, J. Am. Vet. Med. Assoc. (1954) 124:259-261.

[18] Hanssens F.P., Nauwynck H.J., Pensaert M.B., Involvement of membrane-bound viral glycoproteins in adhesion of pseudorabies virus-infected cells, J. Virol. (1993) 67:4492-4496.

[19] Iglesias G., Pijoan C., Molitor T., Interactions of pseudorabies virus with swine alveolar macrophages I: virus replication, Arch. Virol. (1989) 104:107-115.
[20] Jöns A., Gerdts V., Lange E., Kaden V., Mettenleiter T.C., Attenuation of dUTPase deficient pseudorabies virus for the natural host, Vet. Microbiol. (1997) 56:47-54.

[21] Kaplan A.S., Vatter A.E., A comparison of herpes simplex and pseudorabies viruses, Virology (1959) 7:394-407.

[22] Kaliman A.V., Boldogkoi Z., Fodor I., Large and small subunits of the Aujeszky's disease virus ribonucleotide reductase: nucleotide sequence and putative structure, Biochim. Biophys. Acta (1994) 1219:151-156.

[23] Kimman T.G., Pol J.M., de Wind N., Oei-Lie N., Berns A.J., Gielkens A.L., Role of different genes in the virulence and pathogenesis of Aujeszky's disease virus, Vet. Microbiol. (1992) 33:45-52.

[24] Kimman T.G., Immunological protection against pseudorabies virus, in: Aujeszky's disease, Proceedings of OIE Symposium, Bangkok, Thailand, 1994, pp. 11-22.

[25] Kit S., Kit M., Bartkoski M.J., Dees G., Genetically engineered pseudorabies virus vaccine with deletions in thymidine kinase and glycoprotein genes, Cold Spring Harbor Symposium Vaccines 87, Pseudorabies Vaccines, 1987, pp. 345-349.

[26] Klupp B.G., Fuchs W., Weiland E., Mettenleiter T.C., Pseudorabies virus glycoprotein L is necessary for virus infectivity but dispensable for virion localization of glycoprotein H, J. Virol. (1997) 71:7687-7695

[27] Klupp B.G., Fuchs W., Granzow H., Nixdorf R., Mettenleiter T.C., The pseudorabies virus UL36 tegument protein physically interacts with the UL37 protein, J. Virol. (2002) 76:3065-3071.

[28] Klupp B.G., Hengartner C.J., Mettenleiter T.C., Enquist L.W., Complete, annotated sequence of the pseudorabies virus genome, $\mathrm{J}$. Virol. (2004) 78:424-440.

[29] Klupp B.G., Altenschmidt J., Granzow H., Fuchs W., Mettenleiter T.C., Identification and characterization of the pseudorabies virus UL43 protein, Virology (2005) 334:224-233.

[30] Köhler M., Köhler W., Zentralblatt für Bakteriologie - 100 years ago Aladar Aujeszky detects a "new" disease - or: It was the cow and not the sow, Int. J. Med. Microbiol. (2003) 292:423-427.

[31] Kritas S.K., Pensaert M.B., Mettenleiter T.C., Role of envelope glycoproteins gI, 
gp63 and gIII in the invasion and spread of Aujeszky's disease virus in the maxillary nerve and trigeminal ganglion of pigs after intranasal inoculation, J. Gen. Virol. (1994) 76:2063-2066.

[32] Kritas S.K., Pensaert M.B., Mettenleiter T.C., Invasion and spread of single glycoprotein deleted mutants of Aujesky's disease virus (PRV) in the trigeminal nervous pathway of pigs after intranasal inoculation, Vet. Microbiol. (1994) 40:323-334.

[33] Lehman I.R., Boehmer P.E., Replication of herpes simplex virus DNA, J. Biol. Chem. (1999) 274:28059-28062.

[34] McFerran J.B., Dow C., The excretion of Aujeszky's disease virus by experimentally infected pigs, Res. Vet. Sci. (1964) 5:405410.

[35] Mettenleiter T.C., Zsak L., Zuckermann F., Sugg N., Kern H., Ben-Porat T., Interaction of glycoprotein gIII with a cellular heparinlike substance mediates adsorption of pseudorabies virus, J. Virol. (1990) 64:278-286.

[36] Mettenleiter T.C., Aujeszky's disease (pseudorabies) virus: the virus and molecular pathogenesis - State of the art, June 1999, Vet. Res. (2000) 31:99-115.

[37] Mettenleiter T.C., Brief overview on cellular virus receptors, Virus Res. (2002) 82:3-8.

[38] Mettenleiter T.C., Intriguing interplay between viral proteins during herpesvirus assembly or not: The herpesvirus assembly puzzle, Vet. Microbiol. (2006) 113:163-169.

[39] Miry C., Pensaert M., Aujeszky's disease replication in tonsils and respiratory tract of non-immune and immune pigs, in: van Oirschot J.T. (Ed.), Vaccination and control of Aujeszky's disease, 1989, pp. 163-173.

[40] Mulder W., Pol J., Kimman T., Kok G., Priem J., Peeters B., Glycoprotein D-negative pseudorabies virus can spread transneuronally via direct neuron-to-neuron transmission in its natural host, the pig, but not after additional inactivation of $\mathrm{gE}$ or $\mathrm{gI}$, J. Virol. (1996) 70:2191-2200.

[41] Nauwynck H.J., Pensaert M.B., Abortion induced by cell-associated pseudorabies virus in vaccinated sows, Am. J. Vet. Res. (1992) 53:489-493.

[42] Nauwynck H.J., The cell-associated spread of Aujeszky's disease virus and its possible role in the pathogenesis of abortion in vaccinated sows, Ph.D. thesis, Ghent University, Belgium, 1993.
[43] Nauwynck H.J., Pensaert M.B., Cell-free and cell-associated viremia in pigs after oronasal infection with Aujeszky's disease virus, Vet. Microbiol. (1995) 43:307-314.

[44] Newcomb W.N., Homa F.L., Thomsen D.R., Trus B.L., Cheng N., Steven A., Booy F., Brown J.C., Assembly of the herpes simplex virus procapsid from purified components and identification of small complexes containing the major capsid and scaffolding proteins, J. Virol. (1999) 73:4239-4250.

[45] Ono E., Watanabe S., Nikami H., Tasaki T., Kida H., Pseudorabies virus (PrV) early protein 0 activates $\operatorname{PrV}$ gene transcription in combination with the immediate-early protein IE180 and enhances the infectivity of PrV genomic DNA, Vet. Microbiol. (1998) 63:99-107.

[46] Ou C.J., Wong M.L., Chang T.J., A TEF1-element is required for activation of the promoter of pseudorabies virus glycoprotein X gene by IE180, Virus Genes (2002) 25:241-253.

[47] Pensaert M.B., Miry C., Biront P., Castryck F., De Roose P., Robijns J., Segers E., Evolution of Aujeszky's disease in Belgium (1974-1987), Flemish Vet. J. (1987) 56:425432.

[48] Pensaert M.B., De Smet K., De Waele K., Extent and duration of virulent virus excretion upon challenge of pigs vaccinated with different glycoprotein-deleted Aujeszky's disease vaccines, Vet. Microbiol. (1990) 22:107-117

[49] Pensaert M.B., Labarque G., Favoreel H., Nauwynck H., Aujeszky's disease vaccination and differentiation of vaccinated from infected pigs, Dev. Biol. (Basel) (2004) 119:243-254.

[50] Pittler M., The occurrence and control of Aujeszky's disease in the Federal Republic of Germany, in: Wittmann G., Hall S.A. (Eds.), Current topics in veterinary medicine and animal science, Martinus Nijhoff, vol. 17, 1982, pp. 259-265.

[51] Pol J.M.A., Gielkens A.L.J., van Oirschot J.T., Comparative pathogenesis of three strains of pseudorabies virus in pigs, Microb. Pathog. (1989) 7:361-371.

[52] Pol J.M., Broekhuysen-Davies J.M., Wagenaar F., La Bonnardière C., The influence of porcine recombinant interferonalpha 1 on pseudorabies virus infection of porcine nasal mucosa in vitro, J. Gen. Virol. (1991) 72:933-938 
[53] Rauh I., Mettenleiter T.C., Pseudorabies virus glycoproteins gII and gp50 are essential for virus penetration, J. Virol. (1991) 65:5348-5356.

[54] Reagan R.L., Schenk D.M., Harmon M.P., Brueckner A.L., Morphological observations by electron microscopy of pseudorabies virus (Aujeszky strain) after propagation in the rabbit, Am. J. Vet. Res. (1952) 13:577578.

[55] Sabin A.B., Studies on the B virus. I. The immunological identity of a virus isolated from a human case of ascending myelitis associated with visceral necrosis, Br. J. Exp. Pathol. (1934) 15:248-268.

[56] Sabo A., Rajcani J., Blaskovic D., Studies on the pathogenesis of Aujeszky's disease. I. Distribution of the virulent virus in piglets after peroral infection, Acta Virol. (1968) 12:214-221.

[57] Sabo A., Rajcani J., Blaskovic D., Studies on the pathogenesis of Aujeszky's disease. III. The distribution of virulent virus in piglets after intranasal infection, Acta Virol. (1969) 13:407-414.

[58] Schmiedhoffer J., Beiträge zur Pathologie der infektiösen Bulbär paralyse (Aujeszkyschen Krankheit), Z. Infekt. Krankh. Parasit. Hyg. Haustier (1910) 8:383-405.

[59] Schwartz J.A., Brittle E.E., Reynolds A.E., Enquist L.W., Silverstein S.J., UL54-null pseudorabies virus is attenuated in mice but productively infects cells in culture, J. Virol. (2006) 80:769-784.

[60] Shope R.E., An experimental study of "mad itch" with especial reference to its relationship to pseudorabies, J. Exp. Med. (1931) 54:233-248.

[61] Shope R.E., Pseudorabies is a contagious disease in swine, Science (1934) 80:102103.

[62] Smith G.A., Enquist L.W., Break ins and break outs: viral interaction with the cytoskeleton of mammalian cells, Annu. Rev. Cell Dev. Biol. (2002) 18:135-161.

[63] Spear P.G., Eisenberg R.J., Cohen G.H., Three classes of cell surface receptors for alphaherpesvirus entry, Virology (2000) 275:1-8.

[64] Strebel M., Eine eigenthümliche Juckkrankheit beim Rinde, Schweiz. Arch. Tierheilk. (1889) 31:125-129.
[65] Taharaguchi S., Inoue H., Ono E., Kida H., Yamada S., Shimizu Y., Mapping of transcriptional regulatory domains of pseudorabies virus immediate-early protein, Arch. Virol. (1994) 137:289-302.

[66] Toma B., Le Turdu Y., Ursache R., Bernard F., Rose R., David C., Metianu T., Renault L., Gilbert Y., Duée J.P., Épidémiologie descriptive de la maladie d'Aujeszky en France en 1977, Rec. Méd. Vét. (1985) 154:681685.

[67] Van de Walle G.R., Favoreel H.W., Nauwynck H.J., Mettenleiter T.C., Pensaert M.B., Transmission of pseudorabies virus from immune-masked blood monocytes to endothelial cells, J. Gen. Virol. (2003) 84:629-637.

[68] Van de Walle G.R., Favoreel H.W., Nauwynck H.J., Pensaert M.B., Antibodyinduced internalization of viral glycoproteins and $\mathrm{gE}-\mathrm{gI} \mathrm{Fc}$ receptor activity protect pseudorabies virus-infected monocytes from efficient complement-mediated lysis, J. Gen. Virol. (2003) 84:939-947.

[69] Van Minnebruggen G., Favoreel H.W., Jacobs L., Nauwynck H.J., Pseudorabies virus US3 protein kinase mediates actin stress fiber breakdown, J. Virol. (2003) 77:9074-9080.

[70] Vannier P., Hutet E., Bourgueil E., Cariolet R., Level of virulent virus excreted by infected pigs previously vaccinated with different glycoprotein deleted Aujeszky's disease vaccines, Vet. Microbiol. (1991) 29:213 223.

[71] Van Oirschot J.T., Kaashoek M.J., Rijsewijk F.A., Stegeman J.A., The use of marker vaccines in eradication of herpesviruses, J. Biotechnol. (1996) 44:75-81.

[72] Wittmann G., Jakubik J., Ahl R., Multiplication and distribution of Aujeszky's disease (pseudorabies) virus in vaccinated and non-vaccinated pigs after intranasal infection, Arch. Virol. (1980) 66:227-240.

[73] Wong M.L., Ho T.Y., Huang J.H., Hsiang C.Y., Chang T.J., Stimulation of type I DNA topoisomerase gene expression by pseudorabies virus, Arch. Virol. (1997) 142:20992105.

[74] Wu L., Berk A.J., Transcriptional activation by the pseudorabies virus immediate early protein requires the TATA box element in the adenovirus 2 E1B promoter, Virology (1988) 167:318-322. 